\section{Hermetic dialogue}

The Ash Wednesday Supper: La Cena de le Ceneri. By Girdano Bruno. Pp. 174. (Mouton: The Hague and Paris, 1975.) 28 Dutch guilders.

The Ash Wednesday Supper (La Cena de le Ceneri) is one of six Italian dialogues written by Giordano Bruno for the Elizabethan court when he visited London in 1584-85. The underlying purpose of the dialogue was at once religious and political. Bruno hoped to achieve a union between England and France through a hermetic interpretation of the Christian religion. Historians of sixteenth century intellectual history have found Bruno's work interesting not only for this reason, but because it involves an extended metaphor grounded in Copernican astronomy. Professor Jaki's translation of $L a$ Cena is based on an edition by Giovanni Aquilecchia of 1955, rather than on the later and fuller edition by the same editor. Professor Jaki makes a very stern critic of Bruno's science in many of its details, and might have been a more sympathetic commentator had he not insisted on treating Bruno as something he was not, namely a scientist in the modern sense of the word. It will cause no-one surprise to find that Bruno does not conform to the canons of modern scientific thought, and history is not likely to be much illuminated by showing how Bruno failed to do so. Does it matter that Bruno did not anticipate Olbers' paradox? Professor Jaki's translation will certainly make the work of Bruno more accessible to an English-speaking audience. The commentary propagates one or two old myths, such as that of the 50 astronomers engaged by Alfonso of Castile to revise the Ptolemaic astronomical tables. For the most part, the translation reads well, but there are a number of points where the very sense of the English should have drawn attention to a mistranslation. Lewis and Short will soon put right the translation offered for Neque id sine lepore et gratia, which can hardly mean "Not without a rabbit and thanks"! J. D. North

\section{Porphyrins}

Porphyrins and Metalloporphyrins. Edited by K. M. Smith. New Edition based on the original volume by $J$. E. Falk. Pp. xxiii +910. Elsevier Scientific: Amsterdam, Oxford and New York, 1975.) Dfl. 275; \$114.50.

THIS book will be warmly welcomed by all who work in the area of porphyrins and metalloporphyrins, as it brings up to date material covered by Falk, while changing the emphasis somewhat to cover synthetic aspects and applications of spectroscopic methods. Throughout, the authors have taken care to emphasise biological relevance, and a section dealing with porphyrin biosynthesis and catabolism is included. Apart from a lack of coverage of catalytic properties of metalloporphyrins, the choice of material and its distribution among the various chapters is excellent. The editor is to be further congratulated on the coordination and cross-referencing between various chapters and the absence of significant overlap from different contributors. The presentation is good with many helpful diagrams and formulae, but there is no distinction in the type-setting between different classes of subheadings and, in parts, this is confusing. The text contains an abundance of references to reviews and original papers up to late 1974 .

The first section deals with nomenclature and general features of structure, stability and spectra, fol- lowed by a summary of recent developments in chemical synthesis. Section 2 contains chapters on biosynthesis (including an excellent account of the 'type III isomer problem') and degradation to bilins. A comprehensive account of the coordination chemistry of porphyrins including static and dynamic aspects is followed by a section on methods for determination of molecular structure. This contains a wealth of information on X-ray, mass spectrometric, infrared and Raman studies and, notably, a detailed discussion of nuclear magnetic resonance to porphyrins, metalloporphyrins and related compounds. Applications of electron spin resonance and Mossbauer spectroscopy are considered in subsequent chapters. Later sections deal with chemical reactivity (including developments in photochemistry) and with structural analogues of porphyrins. The book concludes with a detailed and useful section on laboratory methods.

At $\$ 114.50$, very few workers in the field will acquire a personal copy and even libraries may prove reluctant purchasers - an unfortunate situation as such a uscful book should be within reach of all interested in this field. The problem is only slightly mollified by the news that the Laboratory Methods section is to be published separately. It is to be hoped that a less expensive edition, perhaps in paperback, will soon be forthcoming.

\section{Understanding information processing}

Understanding Language : An Information-Processing Analysis of Speech Perception, Reading and Psycholinguistics. Edited by Dominic W. Massaro. Pp. xii +439. (Academic: New York and London, September 1975.) \$16.50; $£ 7.90$.

THIS volume comprises eleven chapters; Massaro is an author of six and most of the remainder are by students of his. The book has been edited purposefully so that the coverage and level of the chapters cohere. There are some highly positive general attributes of the book. A wide literature is competently summarised and the references are quite comprehensive as well as up-to-date. To focus a set of reviews of aspects of information processing on the central theme of language is worthwhile.

Massaro's introductory chapter is one of the weaker ones, expounding an overview from a basic flow diagram of the sort which shows how to get from sound waves to abstract memory using only three boxes. Such diagrams are at best a harmless device for distinguishing groups of experiments. Too often they confuse the hierarchical structure of knowledge with the psychological processes by which it is arrived at. This chapter seems to me superficial without being usefully introductory.

The speech perception section begins with a much needed chapter on basic articulatory and acoustic dimensions which facilitates access to a literature which usually takes these as read. Two chapters on acoustic features and temporal factors lead to a review of major theories. Three chapters on reading cover elementary feature processing, word recognition and eye movements. Too much space is devoted to the scholastic enterprise of compiling letter feature lists but the discussion of redundancy utilisation is thorough. Massaro denies the use of lexical redundancy, probably incorrectly. The closing section on psycholinguistics reviews matters adequately treated elsewhere but adds completeness to the volume.

This book offers few significant theoretical insights but it provides a very competent review of an important and mobile area of research and will be highly useful to the advanced undergraduate or specialist for two or three years.

Leslie Henderson 